
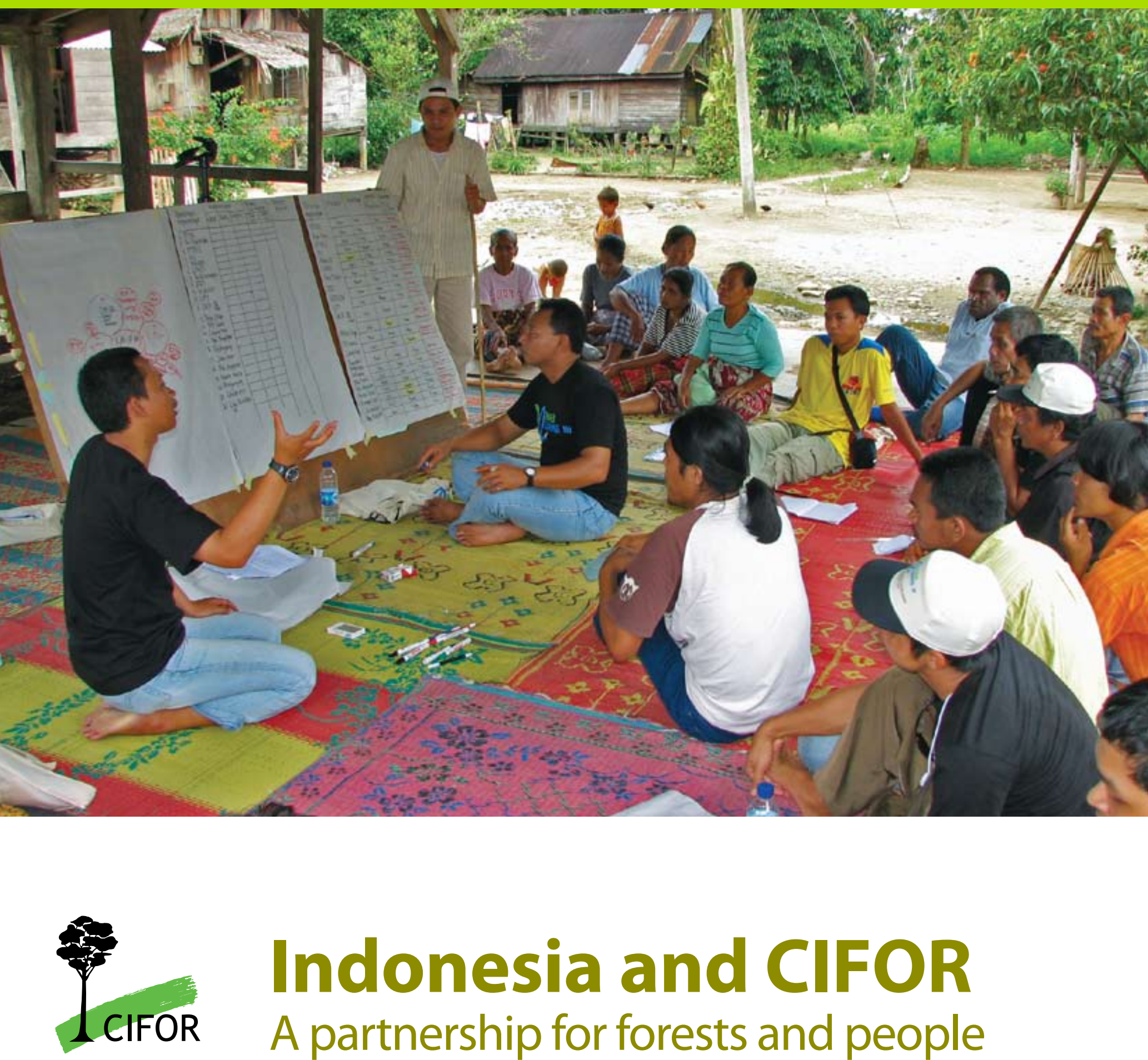

\title{
Indonesia and CIFOR A partnership for forests and people
}




\section{Indonesia and CIFOR A partnership for forests and people}

Indonesia, steward of a vast expanse of tropical forest, is the ideal home for CIFOR. CIFOR, committed to science for forests and people, is the perfect partner for Indonesia. Together, we have a 13-year history of collaboration in research on behalf of forests and the people who depend on them. And we will share an increasingly intertwined future as the world looks beyond traditional issues around forests to confront their growing role in mitigating and adapting to climate change.

\section{CIFOR: Providing sound science for the world's forests}

Our vision is a world where forests are high on the political agenda and people recognise their true value for livelihoods and ecosystems. We believe that decisions affecting forests should be based on solid science and principles of good governance. The perspectives of developing countries and people who depend on forests should be reflected in these decisions.

CIFOR stands for the Center for International Forestry Research. It is the only institute in the world with a mandate to perform and disseminate research on sustainable management and use of forests and the wellbeing of people who depend on them.

We conduct research to inform policies and practices affecting forests in Indonesia and other developing countries. Our work

Figure 1. Number of Indonesian staff

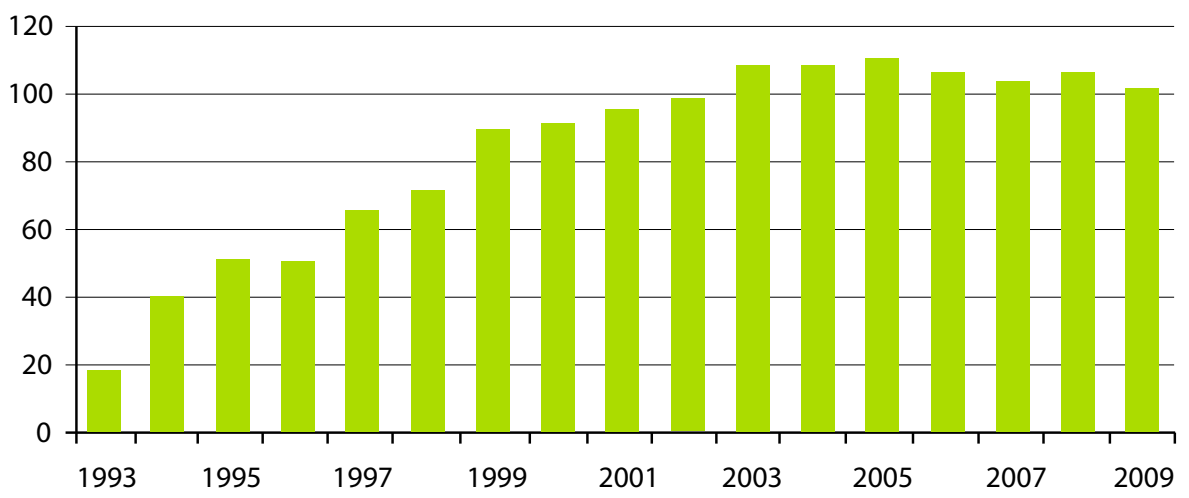

2 | Indonesia and CIFOR 


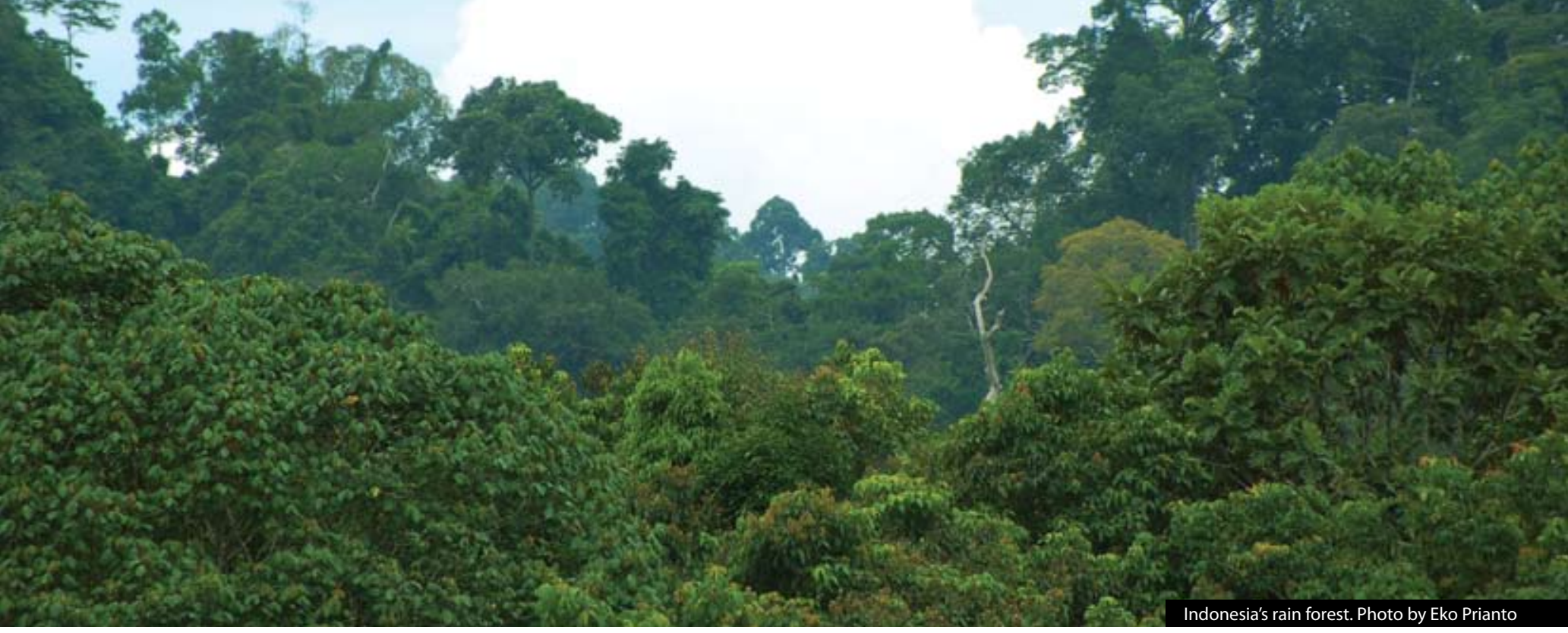

explores biological, physical, economic and social factors in an interdisciplinary way, emphasising sustainable forest management in parallel with sustainable livelihoods.

CIFOR was founded in 1993 in response to global concerns about massive deforestation in the tropics. Headquartered in Bogor since its founding, CIFOR works in more than 30 countries. We are one of 15 centres of the Consultative Group on International Agricultural Research, or CGIAR.

Like the other centres, CIFOR contributes to the CGIAR mandate, which is to achieve sustainable food security and reduce poverty in developing countries through scientific research and related activities in agriculture, forestry, fisheries, policy and environment.

\section{Working together}

Indonesia's experience in managing its immense tropical forest gives it an important role in the global forestry context. Since 1995, CIFOR and Indonesia have worked together on almost 100 projects. CIFOR has invested more than US \$42 million on research in Indonesia more than in any other country.

The broad purpose of our collaboration is sustainable forest management, which aims to conserve the forest while simultaneously deriving from it goods and services that help alleviate poverty. This approach safeguards the biological diversity in primary forests, protecting it for future generations. Joint projects with a variety of Indonesian partners help to spread the message about strategies for benefitting from forests in a smart way. All countries harbouring tropical forests share a similar goal, so our collaboration provides lessons for forest governance far beyond Indonesia's borders.

In addition to the traditional range of forestry issues - from management policies to improvements in logging techniques to tenure rights - our work together is expanding to climate change issues. The rapidly growing area of

A partnership for forests and people | $\mathbf{3}$ 
Figure 2. Number of Indonesian employees by category

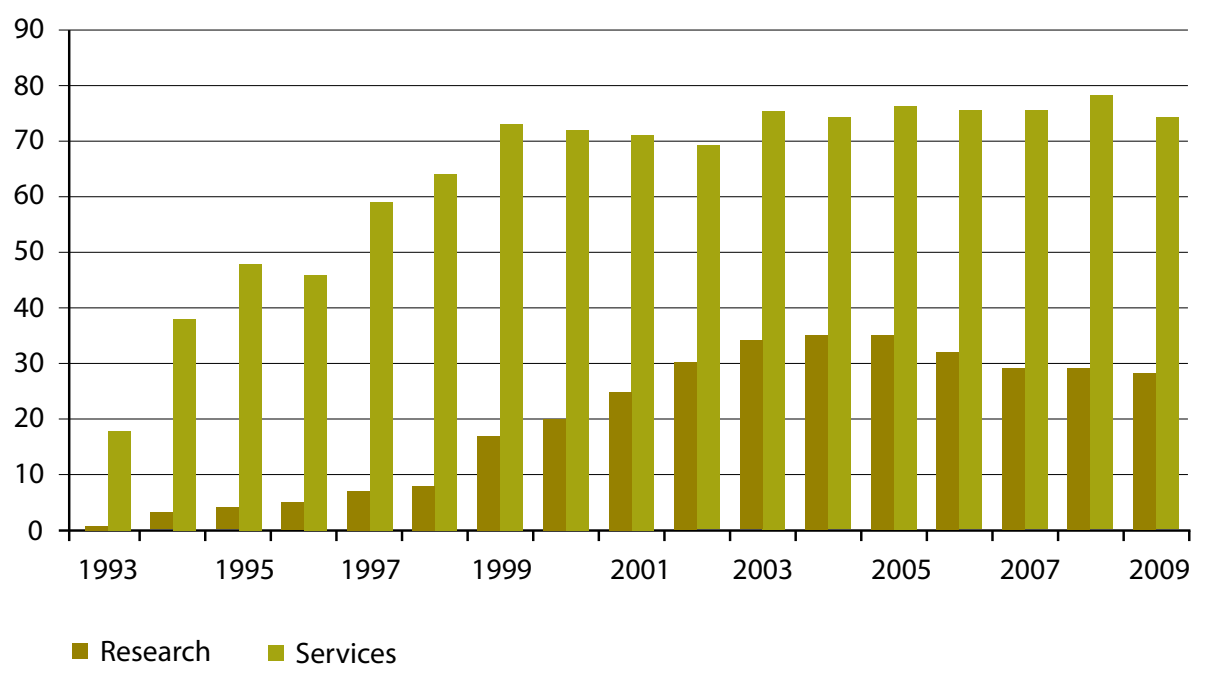

reducing emissions from deforestation and forest degradation and other forms of climate change mitigation and adaptation could bring new opportunities for joint learning and project collaboration.

Along with our key partner, the Ministry of Forestry and its national research centre, FORDA, we collaborate with other government agencies, nongovernmental organisations and the private sector working on forestry and other natural resource issues. Joint project implementation is one opportunity for capacity building. We also hold workshops, supervise graduate students and disseminate research findings and methodologies.

\section{- CIFOR spent US \$42.8 million in Indonesia from 1999 to 2008.}

- Between 2000 and 2008, CIFOR held 132 workshops and training events to benefit Indonesian partners.

4 | Indonesia and CIFOR 


\section{Building a cadre of forest professionals}

The health of a nation's forests depends on the people who manage them. But in today's rapidly shrinking world the stewardship of the forest has gone global. The next generation of forest guardians will need a diverse mix of skills as they face challenges far beyond the canopy. Because of Indonesia's key role on the world forestry stage, its forest professionals will have a global impact no matter where they work, in Indonesia or beyond.

We have helped to develop the skills of the next generation of forest stewards. Among the 100+ Indonesians employed by CIFOR, more than a quarter are researchers. Twenty-four Indonesian staff members have obtained or are pursuing graduate degrees, and six have recently begun a 2-year accelerated staff development programme.
Table 1. CIFOR's partners in Indonesia through 2008

\begin{tabular}{lc}
\hline Category & Number \\
Government & 80 \\
University & 24 \\
Civil society groups and & \\
international organisations & 96 \\
Private sector & 21 \\
Media & 6 \\
\hline
\end{tabular}

Since its founding, CIFOR has supported professional development activities for both Indonesian staff and partners, in the country and abroad. These include individual and group workshops as well as technical development seminars for both researchers and support services staff. We have also provided education loans and flexible work arrangements to

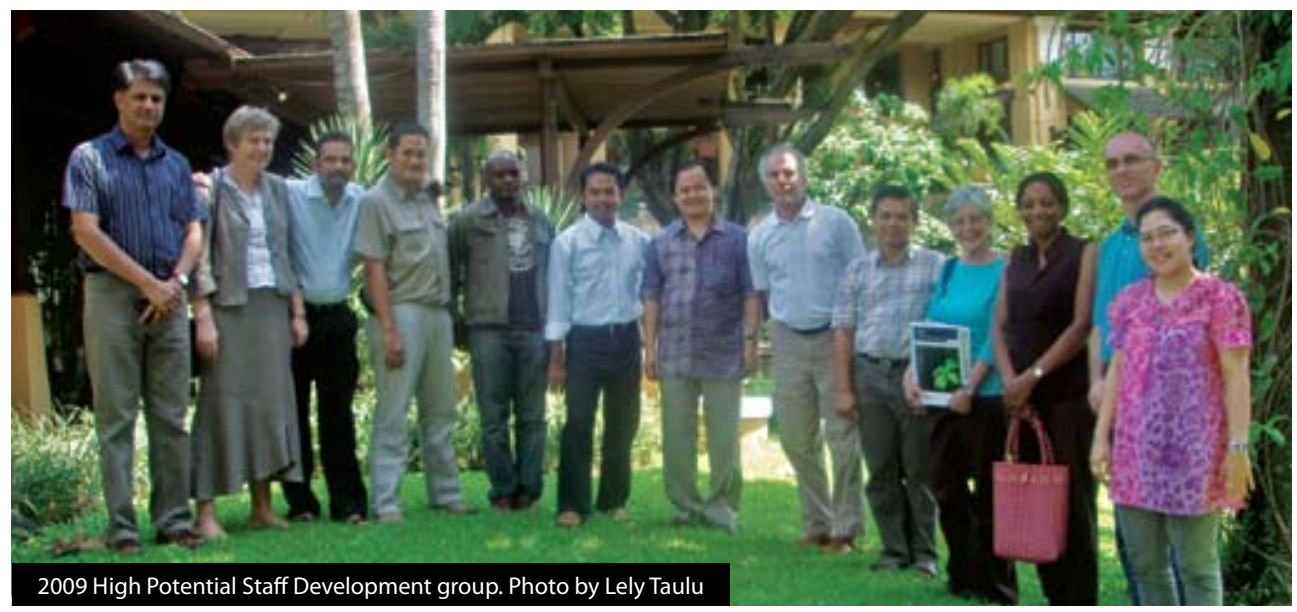

A partnership for forests and people $\mathbf{5}$ 
"I was awarded a post-

doctoral fellowship at

CIFOR in 1996.

I conducted research

until 2000 on the

impact of logging on

biodiversity in Central

Kalimantan. Working

along with well-

respected scientists

gave me a different

angle on forestry and

conservation issues,

and it helped me

frame solutions to

those issues based on science."

Titiek Setyawati Research Coordinator for Conservation of Flora, Fauna and Microorganisms, FORDA our national staff pursuing degrees at Indonesian universities.

More than 150 Indonesians have served as interns at $\mathrm{CIFOR}$, both young researchers and experienced professionals, who benefit from scientific guidance and professional collaboration at our research sites. Some internships cover short-term research, while others serve students pursuing bachelor's and advanced degrees.

In 2008, we started a considerably expanded staff development programme aimed at providing growth opportunities to high-potential staff members across the organisation. It aims to identify and provide structured learning opportunities for those who have shown the potential to move from national to regional or from regional to global level, or into senior research and management positions. An individual multiyear programme is developed for each participant, with relevant training and ongoing mentoring.

\section{Learning to see the big picture: Multidisciplinary landscape assessment}

Much of our work in Indonesia either directly or indirectly builds the skills of the people who derive their livelihoods from the forest.

Today, with competing demands for forest lands steadily increasing, they need a broader range of skills. To manage a forest sustainably requires understanding all of its components and the lives of the people in it - and how they fit together.

A tool for developing this understanding is multidisciplinary landscape assessment.
It is a participatory approach for collecting and analysing data about natural resources and communities, as well as the perceptions of local people on the importance and use of those resources.

Mamberamo, a remote area in West Papua, has 7000 people and 8 million hectares of mostly pristine forest. Conservation International is working with Indonesia to make it a flagship conservation zone. The goal is to help protect its extraordinary biodiversity from the threats that roads and tree plantations will eventually bring.

Table 2. Number of Indonesian students in mentoring programmes, 1993-2009

\begin{tabular}{lc}
\hline Degree & $\begin{array}{c}\text { Number of } \\
\text { students }\end{array}$ \\
\hline High School & 1 \\
Associate's & 13 \\
Bachelor's & 81 \\
Master's & 37 \\
Doctoral & 24 \\
Total & 156 \\
\hline
\end{tabular}

CIFOR was asked to conduct a training course in multidisciplinary landscape assessment for government environmental officials, students and academics from Mamberamo or working in the area. With its demonstrated ability to foster trust between communities and officials, the approach leads to more win-win decisions. We worked with trainees and villagers to build skills in the assessment techniques. A particularly important component was surveying and compiling local opinions on the threats to biodiversity, natural resource management and conservation and land tenure. 


\section{Managing forests for a productive future: Reduced impact logging}

Conserving the forest for future generations calls for smarter logging that leaves a far smaller footprint on the forest. Reduced impact logging requires minimising impacts at each step, from planning and road engineering to workforce training and harvest assessment.

The multiyear Bulungan model forest project began in 1997 in the district of Malinau. Reduced impact logging practices were developed by CIFOR and its partners, including the Government's Forest Research and Development Agency and the state-owned forestry company, PT Inhutani II, along with local representatives of Malinau District.
A trial implementation provided many lessons, and a cost-benefit study was conducted at the same time. Following the trial, PT Inhutani II has worked to incorporate the lessons in its concessions.

CIFOR's role has focused on capacity strengthening. We have offered training courses for communities and district officials as well as timber companies.

A key result of this collaboration was a decree issued by the Ministry of Forestry requiring all timber companies in Indonesia to implement reduced impact logging. The outcome of this project is documented in a book, Pembalakan Ramah Lingkungan (Reduced Impact Logging), published in 2007.

\section{- Since 1993, CIFOR has supported 61 master's or doctoral theses.}

\section{Of the publications released by CIFOR in 2008, 35 had Indonesian coauthors.}




\section{Reaping the benefits of CIFOR research}

"Our academic experts, government authorities and forest

practitioners have

had easy access to science from CIFOR's publications, which

are useful both as academic references and as aids to policy and legislative improvement to further sustainable forest management."

Djamaludin Suryohadikusumo Minister of Forestry 1993-1998
CIFOR's mandate is global, but there is no better laboratory than Indonesia for addressing worldwide humid tropical forestry issues. With a large portion of forest cover of global and national significance, Indonesia faces the same issues that concern other countries with tropical forest reserves all over the world. The knowledge developed in addressing local issues contributes to global solutions. As a result, Indonesia reaps the first (and most) benefits from CIFOR's work.

Joint CIFOR-Indonesia projects represent the entire range of CIFOR's research agenda. And our work with research institutes, universities and NGOs helps

Figure 3. CIFOR research grants to Indonesian institutions, in US dollars

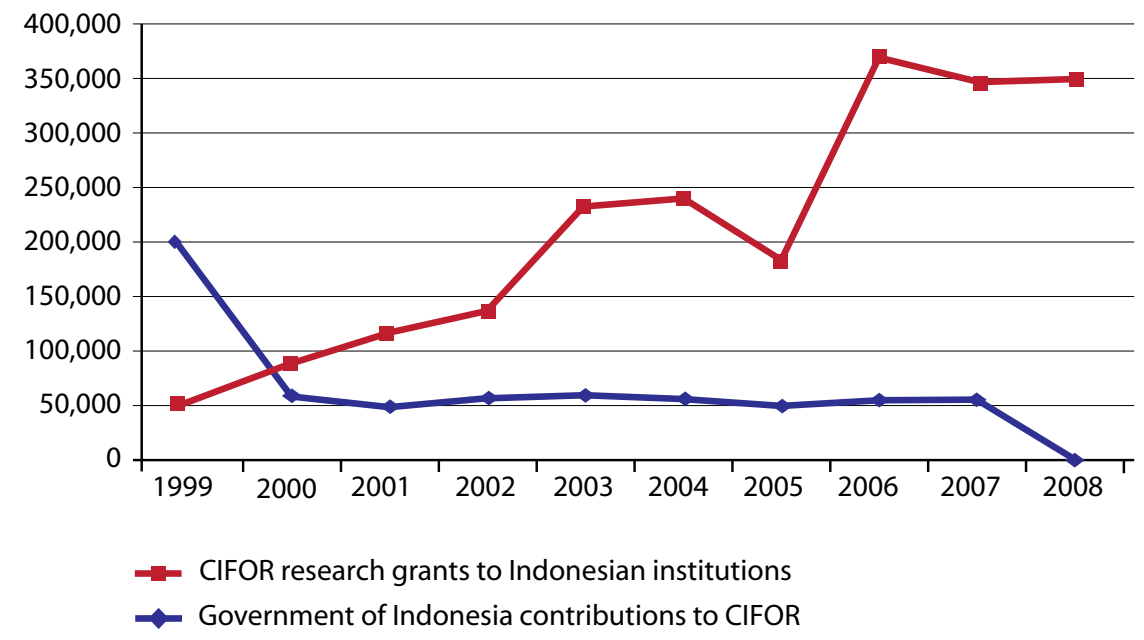

8 | Indonesia and CIFOR build the skills of national experts. This collaboration also brings a financial contribution: The value of grants to Indonesian research institutes totalled US \$2.1 million over the 10-year period ending in 2008.

\section{Helping smallholders compete with bigger players}

Over the past decade CIFOR has been working to help smallholder and community forestry gain access to the timber industry, long dominated by large and multinational companies. In Indonesia we have focused on analysing 


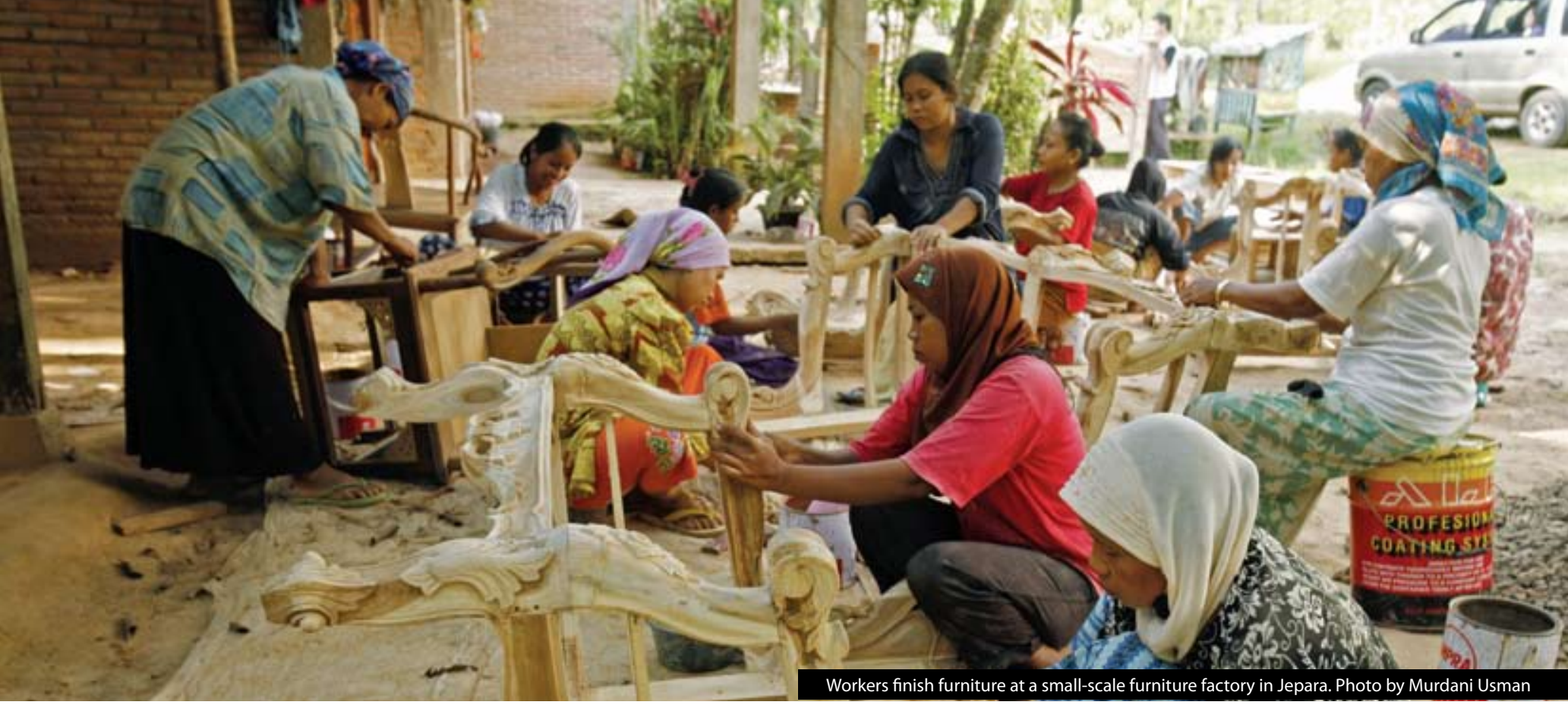

the impediments, particularly regulatory constraints that limit smallholder participation. A key obstacle is transport, with its high transaction costs. To ensure legal log sourcing, Indonesia, like many countries, requires a transport permit from the district office, requiring associated fees and petty bribes. Research found that village offices could provide permits at lower transaction costs than district offices without sacrificing the accuracy of log sourcing.

To spread awareness of these findings, CIFOR facilitated the establishment of the Community-Company Forest Link, called ComForLink. This forum brings together companies, smallholders and local communities, strengthening their ability to influence the Ministry of Forestry. The Ministry then asked ComForLink to help introduce less bureaucratic systems in order to encourage smallholder plantations.
ComForLink's participation in policy dialogues contributed to the Ministry's issuance of a new regulation in 2007 simplifying marketing procedures for the 18 tree species commonly traded by smallholders. Transport permits for these species can now be obtained from village forestry officers, saving time and money for around 3 million small-scale plantation producers.

\section{Innovation in forestry law enforcement}

Collaboration between Indonesia and CIFOR led to a 'first in the world' for Indonesia: It became the first country to define forestry crimes as a moneylaundering offence. This result came from CIFOR's research on financial due diligence in forest-related investments.

\section{"When CIFOR}

conducted its research in Jepara, the furniture industry was close to collapse. CIFOR's presence and its work generated hope and enthusiasm among the craftsman, and it improved the quality of the furniture produced."

Margono

Member, Association of Small-Scale Furniture Producers in Jepara (Asosiasi Pengrajin furniture Kecil Jepara/APKJ) 
Figure 4. Research investment in Indonesia compared to other regions, 2003-2008

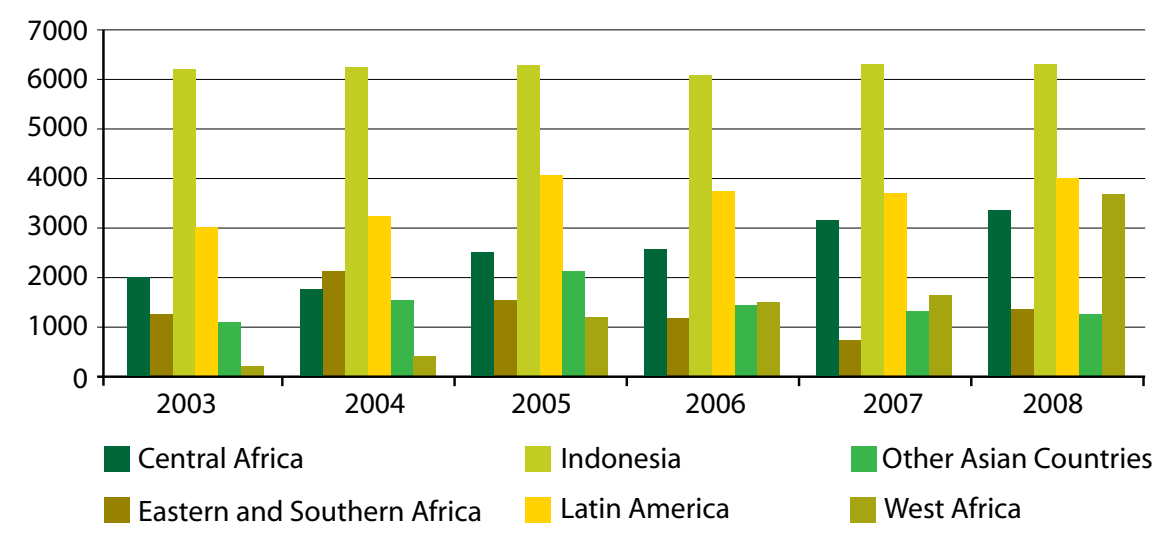

CIFOR's studies were used in formulating policy recommendations that were adapted into a memorandum of understanding between the Ministry of Forestry and the government's Centre for Reporting and Analysis of Financial Transactions. The ministry and the

centre are now working jointly with law enforcement agencies. Policy makers and regulatory agencies in other countries are looking at Indonesia as a pilot case for using laws against money laundering to curtail illegal logging.

- From books and journal articles to software and CD-ROMs, CIFOR has issued more than 600 publications about Indonesia, in Indonesian and English.

- CIFOR spends 37 percent of its research budget in Indonesia.

- Half the publications CIFOR released between 1994 and 2008 concerned issues in Indonesia.

10 | Indonesia and CIFOR 


\section{Addressing the new challenge: Climate change}

Tropical forests have been more in the spotlight in the past decade as scientists have come to understand the magnitude of the link between forests and climate change. This has brought a new level of collaboration between CIFOR and its Indonesian partners-both individuals and organizations, public and private. CIFOR is working to make available existing knowledge about 'what works' and to produce as much new knowledge as possible.

A REDD mechanism is likely to be agreed in the near future, which will vastly increase demand for information about it. With this in mind, CIFOR recently launched a website aimed at publicising REDD actions in Indonesia (http://reddindonesia.org). Created in collaboration with PILI, an Indonesian environmental group, and the Worldwide Fund for Nature, the site is a contribution to the growing national and international discussion of REDD, climate change and forest conservation.

\section{Promoting Indonesian climate change initiatives}

CIFOR and the Ministry of Forestry are working together on many facets of the forest-climate change link. On a policy level, a key step is our Climate Change and Forests Initiative. This partnership aims to ensure that averted deforestation under the upcoming climate protection

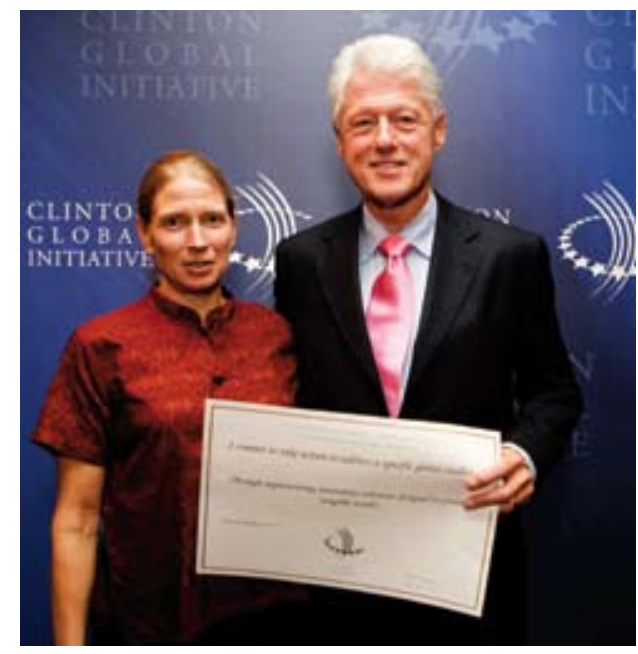

Director General Frances Seymour and former President Bill Clinton. Photo by Ralph

regime is informed by independent research. It will involve CIFOR and the Ministry working with institutions from Africa, Asia and Latin America to perform collaborative research on the role of climate change mitigation and adaptation. The initiative won praise from former U.S. President Bill Clinton. CIFOR and Indonesia were awarded a certificate signed by him applauding the plan and the commitment to ensure that the risks of such policies (are not borne by those least able to afford them).

With Bogor Agricultural University we are developing a collaborative workshop on carbon measurement. This effort includes development of a carbon measurement 
toolkit, which will be produced jointly with FORDA. This is part of a project aimed at supporting implementation of REDD demonstration activities worldwide. We are also participating with the Ministry of Forestry in the Indonesia Forest Climate Alliance.

\section{Regional adaptation efforts}

CIFOR and Indonesia are also involved in a regional collaborative project to assess the vulnerability of forest ecosystems to climate change and variability. The project is giving special attention to wildfires and landslides. Implementing partners at the national level are Ministry of Environment, Ministry of Forestry, Indonesian Institute of Sciences (LIPI), National Council on Climate Change, National Institute of Aeronautics and Space (LAPAN), Centre for Vulcanology and Geological Disaster Mitigation, Brawijawaya University and Worldwide Fund for Nature-Indonesia.

The Forest Eleven Forum, launched by Indonesian President Susilo Bambang Yudhoyono, has united leaders of 11 tropical rainforest countries. At a meeting in New York they issued a joint statement resolving to intensify efforts for sustainable forest development while promoting sustainable economic development and poverty eradication. The President's Office asked CIFOR to provide briefing materials for the initiative.

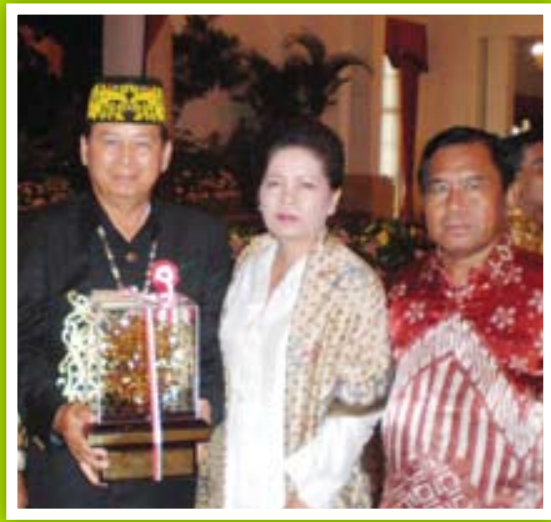

Kalpataru award winner. Photo by Bapedalda
CIFOR helped the village of Setulang win Indonesia's most prestigious environmental award, the Kalpataru, in 2003. The community was awarded for efforts to protect its forests from illegal logging in the face of huge temptations to earn billions of rupiah from the sale of its forest lands. Under the Bulungan model forest project, most research activities were conducted in Setulang village, jointly implemented by CIFOR and the Ministry of Forestry. Research results were used to establish a forest management plan, support capacity building and facilitate the resolution of conflicts with neighbouring villages.

http://www.cifor.cgiar.org/Publications/Corporate/NewsOnline/ NewsOnline33/environmental.htm

CIFOR advances human wellbeing, environmental conservation and equity by conducting research to inform policies and practices that affect forests in developing countries. CIFOR is one of 15 centres within the Consultative Group on International Agricultural Research (CGIAR). CIFOR's headquarters are in Bogor, Indonesia. It also has offices in Asia, Africa and South America.

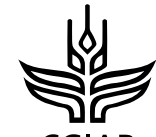

CGIAR

www.cifor.cgiar.org 